Article Type: Short Communication

Handling Editor: Ma Zhijun

Running head: Woodlark responses to ground-disturbance

\title{
Experimental evidence that ground-disturbance benefits Woodlark Lullula arborea
}

\author{
ROBERT W. HAWKES, ${ }^{1 *}$ JENNIFER. SMART, ${ }^{2,3}$ ANDY. BROWN, ${ }^{4}$ HELEN. JONES ${ }^{2}$ \& PAUL M. DOLMAN ${ }^{1}$ \\ ${ }^{1}$ School of Environmental Sciences, University of East Anglia, Norwich, NR4 7TJ, UK \\ ${ }^{2}$ RSPB Centre for Conservation Science, The Lodge, Sandy, Bedfordshire, SG19 2DL, UK \\ ${ }^{3}$ School of Biological Sciences, University of East Anglia, Norwich, NR4 7TJ, UK \\ ${ }^{4}$ Natural England, Suite D Unex House Bourges Boulevard, Peterborough, PE1 ING, UK
}

* Corresponding author:

Email: Robert.Hawkes@uea.ac.uk

To determine whether ground-disturbance increased Woodlark Lullula arborea abundance, we examined responses over three years to four treatments varying in establishment method (shallowor deep-cultivated) and complexity (homogenous or 'complex-mosaics' comprising fallow and recently-cultivated subplots), plus controls, replicated across the UK's largest lowland grass-heath. Abundance increased through the study, and was higher on plots closer to woodland and across all treatments. Within complex-mosaics, Woodlark preferentially used recently-cultivated subplots over one- or two-year-old fallows. Regardless of treatment detail, providing suitable foraging habitat This article has been accepted for publication and undergone full peer review but has not been through the copyediting, typesetting, pagination and proofreading process, which may lead to differences between this version and the Version of Record. Please cite this article as doi: 10.1111/ibi.12696

This article is protected by copyright. All rights reserved. 
within c. $45 \mathrm{~m}$ of woodland, through annual ground-disturbance, can increase Woodlark abundance within lowland grass-heaths characterised by closed swards.

Keywords: Conservation management, grass-heath, lowland heathland, semi-natural habitat Management interventions for birds have been extensively tested in farmland and woodland (e.g. Siriwardena et al. 2007, Holt et al. 2014), but other lowland semi-natural habitats have received less attention. While many studies use observed relationships between species and habitat composition to inform management (van den Berg et al. 2001, Border et al. 2017), experiments that test multiple treatments across different habitats are needed to support best practice (Buckingham et al. 2004).

The Woodlark's Lullula arborea global population is concentrated in Europe (SPEC 2; Burfield \& Van Bommel 2004) where it is protected under Annex 1 of the EC Birds Directive (EC 1979). Although the British population underwent a partial recovery during the late $20^{\text {th }}$ century (Conway et al. 2009), declines in some areas have resumed and the species is classified as Threatened (Stanbury et al. 2017). Most territories in Britain are associated with lowland heathland or plantation forestry (67\% and $32 \%$ respectively, Conway et al. 2009), where the species uses taller vegetation for nesting (Mallord et al. 2007a) and bare-open foraging areas (Bowden 1990, Mallord et al. 2007b). Declines may be linked to the cessation of dynamic processes (e.g. rabbit grazing, turf/litter removal, episodic-cultivation) which historically created early-successional mosaics within lowland heathland. Although the importance of bare ground is known, it is not clear whether treatments that open-up closed swards promote population recovery, nor whether disturbance treatment or habitat type matters.

We assessed the effects of ground-disturbance on Woodlark as an integral part of an extensively replicated, multi-taxa, landscape-scale experiment in the UK's largest lowland grassheath (involving 102 plots, totalling 248 ha, within 3,850 ha of grass-heath). We examined territory numbers (hereafter 'abundance') and habitat use across four treatments, differing in establishment

This article is protected by copyright. All rights reserved. 
method (shallow- or deep-cultivated) and complexity (annually treated 'homogenous plots'; or 'complex-mosaic plots', comprising subplots varying in age and disturbance frequency), while controlling for vegetation type, year and landscape features. We a priori predicted that: (1) complex-mosaics would support the greatest increase in abundance, and (2) recently-cultivated subplots would be preferred within complex-mosaics.

\section{METHODS}

\section{Study site}

The study was carried out from 2015-2017 on the Stanford Military Training Area (STANTA; 076'E, $\left.52^{\circ} 51^{\prime} \mathrm{N}, 3,500 \mathrm{ha}\right)$, Bridgham Heath $\left(0^{\circ} 83^{\prime} \mathrm{E}, 52^{\circ} 44^{\prime} \mathrm{N}, 150 \mathrm{ha}\right)$ and Brettenham Heath $\left(0^{\circ} 83^{\prime} \mathrm{E}\right.$, $52^{\circ} 43^{\prime} \mathrm{N}, 200$ ha), in Eastern England (Fig. S1; for site details, see Appendix S1).

\section{Experimental design}

Across these sites, 66 replicate 2 ha plots (33 deep-cultivated, 33 shallow-cultivated) and 36 uncultivated controls were established in early 2015 (for treatment details, see Appendix S2). Treatments were repeated in early 2016 and 2017, maintaining 26 as 2 ha homogenous plots (13 deep-cultivated, 13 shallow-cultivated) treated annually in the same location, and diversifying 40 as complex-mosaics (20 deep-cultivated, 20 shallow-cultivated), again cultivating 2 ha each year, but half-overlapping and half first-time-cultivation, building up a rotational mosaic of subplots that varied in frequency of, and time since, cultivation. Each complex-mosaic comprised three 1 ha subplots in 2016 and four 1 ha subplots in 2017, that included fallowed (in 2016 one-year-old; in 2017 both one- and two-year-old), first-time-cultivated, and annually-cultivated (Fig. 1). All homogenous and complex-mosaic plots received 2 ha of ground-disturbance treatment each year, representing similar cost; but while homogenous plots remained 2 ha in area, complex-mosaics

This article is protected by copyright. All rights reserved. 
increased to 3 ha in 2016 and 4 ha by 2017. To account for differences in treatment extent between designs and years, monitoring consistently examined a 4 ha area centred on the plot (whether homogenous, complex-mosaic or control), but including sufficient untreated grass-heath to complete 4 ha.

Plots were located in grass-heath, often excluding, but close to ( $95 \%$ within $16 \mathrm{~m})$, scattered trees or scrub (Ulex europaeus). Potential for unexploded ordnance precluded placing grounddisturbance plots in the central 'impact area' of STANTA, restricting treatments to the outer areas of this site and Bridgham and Brettenham Heath (Fig. S1). Control plots were also located in these areas $(n=16)$, and the impact area $(n=20)$. Potential plot locations were mapped based on: (1) underlying soil type (National Soil Resources Institute, Cranfield University), (2) age since last cultivation (Sheail 1979), and (3) indicator plant composition before treatment (Table S1). Using this information, and within constraints of ordnance, plots were allocated randomly to four vegetation strata: (1) calcareous grass-heath of any age (hereafter 'calcareous grass-heath'), (2) young grassheath, (3) intermediate grass-heath, and (4) ancient acid grass-heath (Table S2). Treatments and controls (five groups) were distributed similarly with respect to Latitude and Longitude (KruskalWallis, $H=2.65, P=0.62 ; H=1.23, P=0.87$, respectively; $n=102)$; but due to aggregated distributions of soil types and grass-heath ages, vegetation strata (four groups) was not (Latitude, $H$ $=19.26, P<0.001 ;$ Longitude, $H=47.19, P<0.001 ; n=102)$.

\section{Territory mapping and subplot use}

In each year, three 40-minute visits were made to each 4 ha plot between 14 March and 26 June (days between visits: mean $24 \pm 11 \mathrm{sd}$ ) between dawn and 11:00 during still, dry mornings (Beaufort wind force < 4). During each visit, we recorded Woodlark location and behaviour, initially scanning from a vehicle positioned $>100 \mathrm{~m}$ away, followed by walking through each plot's edge and centre. For complex-mosaics, we also recorded the number of registrations on each subplot; multiple subplots used by the same individual were included as separate registrations. Observations were

This article is protected by copyright. All rights reserved. 
restricted to vehicles on 20 of 936 plot-visits (3 in 2015, 10 in 2016, 7 in 2017; affecting 4 treatment replicates, but not controls) to minimise disturbance to Eurasian Stone-curlew Burhinus oedicnemus; on these occasions, vehicles were repositioned during visits to maximise coverage.

Territories were subsequently identified across the three visits, for each year, following Conway et al. (2009). We recognised territories with registrations (on, or singing above, the plot) from at least two separate visits, but excluded males apparently drawn in to interact briefly with a resident bird.

\section{Analysis}

Separate analyses considered abundance per plot-year: (1) across all three years (2015-2017; with all treated plots classified as homogeneous in 2015 , then homogenous or complex-mosaic thereafter), and (2) during the last two years (2016-2017), when complex-mosaics had accrued (though only in 2017 were all subplots available). Generalised Linear Mixed Models (GLMM), with Poisson error and log-link, considered fixed effects of treatment (5 categories: control, cultivation-method $x$ homogenous vs complex-mosaic), vegetation strata ( 4 categories), and year ( 2 or 3 categories), with plot identity as a random factor. Distance from plot edge to the nearest woodland ( $>0.5$ ha) (potential refuge, Schaefer \& Vogel 2000) and Thetford Forest (Fig. S1; potential population source, Wright et al. 2007), were both entered as covariates.

For occupied complex-mosaics in 2017 only, we related the maximum number of registrations (over three visits) per subplot to sub-treatment (4 categories: first-time-cultivated, annually-cultivated, one-year or two-year fallow), in a GLMM with Poisson error, that incorporated fixed effects of cultivation-method ( 2 categories: shallow- vs deep-cultivation) and vegetation strata, with plot identity as a random factor.

For parsimony, initial categories within vegetation strata, treatment, and sub-treatment variables were combined if: (i) parameter estimates were initially similar, and (ii) their combination did not reduce model performance (Akalike's Information Criterion corrected for small sample size,

This article is protected by copyright. All rights reserved. 
AICc, either reduced, or increased $\leq 2$; Burnham \& Anderson 2002). First, vegetation strata categories were examined within abundance analyses (2015-2017 and 2016-2017) and subplot models that incorporated all other variables. Next, treatment and sub-treatment categories were simplified where possible, within 2016-2017 abundance and 2017 subplot models. Treatment categories were not combined in 2015-2017 abundance models as complex-mosaics were not present every year; thus combined categories would have been confounded with year. Following simplification, for each analysis, the set of candidate models comprising all possible variable combinations were examined using package 'Ime4' (Bates et al. 2017). Models were accepted as best if $\triangle \mathrm{AICC}$ (difference in AICC) relative to all other candidate models was $>2$. Where more than one model lay within $2 \mathrm{AICc}$, we used multi-model inference to estimate model-averaged coefficients, unconditional standard errors, and $95 \%$ confidence intervals across those competing models $<2 \Delta$ AICC, accounting for their Akaike weights (following Burnham \& Andserson 2002), using the package 'MuMIn' (Barton 2018). Candidate variables were deemed to be supported if confidence intervals of the model-averaged parameter did not span zero. Spatial autocorrelation of modelled residuals were examined by Moran's I, separately for each year, using the package 'Ape' (Paradis et al. 2004). All models were run in R (R Core Team 2015).

\section{RESULTS}

In 2015, 2016 and 2017, 10, 25 and 39 territories were associated with plots, respectively; all occupied plots were within $45 \mathrm{~m}$ of woodland. Initial simplification of vegetation strata in abundance models (2015-2017 and 2016-2017) supported combining calcareous with intermediate and young grass-heath (retaining ancient acid as distinct), whilst simplification in 2017 subplot models combined calcareous with intermediate and ancient acid grass-heath (retaining young grass-heath as distinct; Table S3). Subsequent simplification of 2016-2017 abundance models combined all grounddisturbance treatments: cultivation-method $\mathrm{x}$ homogenous/complex-mosaic, simplified to treated

This article is protected by copyright. All rights reserved. 
vs. control (though models retaining complex-mosaics/homogenous were similar; $\Delta \mathrm{AIC}_{\mathrm{c}}=1.9 ;$ Table S3). Simplification of 2017 subplot models combined first-time- with annually-cultivated (hereafter 'recently-cultivated'), and one-year-old with two-year-old fallows (hereafter 'fallows'; Table S3).

Multi-model inference was undertaken for both abundance analyses (2015-2017 and 2016-

2017) as there were several candidate models where $<2 \Delta$ AICC (Table S4). For 2015-2017, abundance increased with year, and was higher on all treated plots (compared to controls) and plots closer to woodland (Fig. 2 \& Table S5). Multi-model inference from 2016-2017 was similar (though treatment categories were combined in this model), but with no support for a difference between the two years (Table S5). Although vegetation strata and distance to Thetford Forest were included in averaged models (2015-2017 and 2016-2017), neither effect was supported (Table S5). Predictions from the 2016-2017 model showed a higher abundance on treatment plots in 2017 , on calcareous, intermediate or young grass-heath, $18 \mathrm{~m}$ from woodland (median plot-woodland distance), compared to controls (treatment, $0.59,95 \% \mathrm{Cl} 0.37-0.81$; control, $0.15,95 \% \mathrm{Cl} 0.03-0.27$ ), whilst plots double this distance from woodland $(36 \mathrm{~m})$ had a lower abundance (treatment, $0.36,95 \% \mathrm{Cl}$ 0.18-0.53; control, $0.09,95 \% \mathrm{Cl} 0.01-0.17$; Fig. 3). Model averaged residuals from the 2015-2017 analyses were spatially autocorrelated (although only in 2017, where Moran's I was small but significant; Moran's I $=0.04, P=0.009$ ), suggesting some variation attributable to a spatially correlated factor not considered in the modelling; nevertheless, we consider inference robust, as treatments and controls were distributed randomly in the landscape and balanced across vegetation strata (Table S2), and effects of treatment and distance to woodland were consistent with the 20162017 model (where there was no spatial autocorrelation).

In 2017, Woodlark were recorded on 21/40 complex-mosaic plots. The best supported model (Table S4), showed more registrations in recently-cultivated than fallow subplots (Fig. 4 \& Table. S6), and on calcareous, intermediate and ancient acid grass-heath (cultivation-method was not supported). Model residuals were not spatially autocorrelated.

This article is protected by copyright. All rights reserved. 


\section{DISCUSSION}

Through an extensively replicated landscape-scale experiment, we have demonstrated that Woodlark responded positively to all ground-disturbance treatments, preferred plots closer to woodland, and selected recently-cultivated subplots within complex-mosaic treatments. Previous research has shown Woodlark require bare-open areas for foraging (Bowden 1990, Sitters et al. 1996, Mallord et al. 2007b, Arlettaz et al. 2012), but as far as we are aware, this is the first time numbers have been influenced experimentally through mechanical interventions.

Contrary to our a priori prediction, when all treatment combinations were available (20162017), abundance was greater on both 'shallow and deep-cultivated treatments' and 'homogenous and complex-mosaic plots', compared to controls, but these treatments did not differ from each other. This might be because: (i) both cultivation-methods created suitable foraging habitat, and (ii) recent-cultivation in a matrix of fallows (complex-mosaics) offers little by way of additional resource to recent-cultivation in a matrix of grass-heath (homogenous plots). Within complex-mosaics, their preference for the barer recently-cultivated subplots (Fig. S2) is consistent with a study from Switzerland, which showed c. 50\% ground vegetation cover is optimal for foraging Woodlark (Arlettaz et al. 2012).

The increase from 2015-2017 was attributed to cumulative colonisation as individuals discovered treated plots (visualised by Fig. S3), consistent with adult fidelity and the known scale of natal dispersal (e.g. up to $11 \mathrm{~km}$; Bowden \& Green 1992). We are confident this accumulation of territories was not due to the increasing size and complexity of the complex-mosaics, as abundance was similar between treatments.

Consistent with evidence from Iberia, where colonisation of previously open habitats by woody vegetation benefitted Woodlark (Sirami et al. 2007), our results demonstrated a preference for plots close to woodland. Schaefer and Vogel (2000) explored the ecological function of fieldforest ecotones for Woodlark, and showed birds fly towards forest when disturbed, stating 'on

This article is protected by copyright. All rights reserved. 
closer examination of anti-predation strategies it became clear that forest edge is not a factor of woodlark-territories, but the habitat of that species.' In Britain, Woodlark are regarded as a species of open-heath and clear-fell forestry; however, their association with woodland edge is important.

\section{Conservation recommendations}

Our experiment suggests that ground-disturbance could represent an important conservation prescription for Woodlark within other lowland grass-heaths. Since all treatments involved annual disturbance, and given their preference for recently-cultivated subplots, annual-cultivation may be necessary (although methods which retain bare ground for longer may require less frequent intervention), regardless of establishment method (complex-mosaic or homogenous; shallowcultivated or deep-cultivated). Interventions should be within c. $45 \mathrm{~m}$ of woodland, but this may deter other potential beneficiaries that prefer open habitats (e.g. Stone-curlew, Johnston 2009). Although Woodlark responded positively to all treatments, the multi-taxa consequences of this management are unclear, although autoecological information indicates it will benefit many scarce species (Dolman et al. 2012, Pedley et al. 2013). We thus advise caution in using a single ground-disturbance prescription until the wider results of our experiment are available.

RSPB and Natural England (NE) funded this work through the Action for Birds in England programme, with support from Defence Infrastructure Organisation (DIO) and Breaking New Ground. We thank DIO, Sheep Enterprise, NE, Richard Evans, STANTA bird group, Dominic Ash and lan Levett for assistance. Cranfield University provided soil data under licence. We are grateful to the editor (Dan Chamberlain) and one anonymous reviewer for helpful comments on an earlier version of this paper.

This article is protected by copyright. All rights reserved. 


\section{REFERENCES}

Arlettaz, R., Maurer, M. L., Mosimann-Kampe, P., Nusslé, S., Abadi, F., Braunisch, V. \& Schaub, M. 2012. New vineyard cultivation practices create patchy ground vegetation, favouring Woodlarks. J. Ornithol. 153: 229-238.

Barton, K. Multi-Model Inference. available at: https://cran.r-project.org/web/packages/MuMln/ (accessed 23 September 2018).

Bates, D., Maechler, M., Bolker, B. \& Walker, S. Linear Mixed-Effects Models using 'Eigen' and S4. available at: https://cran.r-project.org/web/packages/Ime4/ (accessed 3 May 2018).

Border, J. A., Henderson, I. G., Redhead, J. W. \& Hartley, I. R. 2017. Habitat selection by breeding Whinchats Saxicola rubetra at territory and landscape scales. Ibis 159: 139-151.

Bowden, C. 1990. Selection of foraging habitats by Woodlarks (Lullula arborea) nesting in pine plantations. J. Appl. Ecol. 27: 410.

Bowden, C. G. R. \& Green, R. E. 1992. The Ecology and management of Woodlarks on pine plantations in the Thetford and Sandlings forests. Unpublished RSPB report. Sandy.

Buckingham, D. L., Atkinson, P. \& Rook, A. J. 2004. Testing solutions in grass-dominated landscapes: A review of current research. Ibis 146: 163-170.

Burfield, I. \& Van Bommel, F. 2004. Birds in Europe: population, estimates, trends and conservation status, Cambridge: Birdlife International.

Burnham, K. P. \& Anderson, D. R. 2002. Model selection and multi-model inference: a practical information-theoretic approach, New York: Springer.

Conway, G., Wotton, S., Henderson, I., Eaton, M., Drewitt, A. \& Spencer, J. 2009. The status of breeding Woodlarks Lullula arborea in Britain in 2006. Bird Study 56: 310-325.

Dolman, P. M., Panter, C. J. \& Mossman, H. L. 2012. The biodiversity audit approach challenges regional priorities and identifies a mismatch in conservation. J. Appl. Ecol. 49: 986-997.

Holt, C. A., Fuller, R. J. \& Dolman, P. M. 2014. Exclusion of deer affects responses of birds to woodland regeneration in winter and summer. Ibis 156: 116-131.

This article is protected by copyright. All rights reserved. 
Johnston, A. 2009. Demographic analsis of the impact of conservation action on Stone-curlew populations. PhD thesis. Cambridge: University of Cambridge.

Mallord, J. W., Dolman, P. M., Brown, A. \& Sutherland, W. J. 2007a. Nest-site characteristics of Woodlarks Lullula arborea breeding on heathlands in southern England: are there consequences for nest survival and productivity? Bird Study 54: 307-314.

Mallord, J. W., Dolman, P. M., Brown, A. F. \& Sutherland, W. J. 2007b. Linking recreational disturbance to population size in a ground-nesting passerine. J. Appl. Ecol. 44: 185-195.

Paradis, E., Claude, J. \& Strimmer, K. 2004. APE: Analyses of Phylogenetics and Evolution in R language. Bioinformatics 20: 289-290.

Pedley, S. M., Franco, A. M. A., Pankhurst, T. \& Dolman, P. M. 2013. Physical disturbance enhances ecological networks for heathland biota: A multiple taxa experiment. Biol. Conserv. 160: 173182.

R Core Team. 2015. $R$ : a language and environment for statistical computing. Version 3.2.2, Vienna: R Foundation for Statistical Computing.

Schaefer, T. \& Vogel, B. 2000. Why do Woodlarks need field-forest ecotones? - An analysis of possible factors. J. Ornithol. 141: 335-344.

Sheail, J. 1979. Documentary evidence of the changes in the use, management and appreciation of the grass-heaths of Breckland. J. Biogeogr. 6: 277-292.

Sirami, C., Brotons, L. \& Martin, J. 2007. Vegetation and songbird response to land abandonment: From landscape to census plot. Divers. Distrib. 13: 42-52.

Siriwardena, G. M., Stevens, D. K., Anderson, G. Q. A., Vickery, J. A., Calbrade, N. A. \& Dodd, S. 2007. The effect of supplementary winter seed food on breeding populations of farmland birds: evidence from two large-scale experiments. J. Appl. Ecol. 44: 920-932.

Sitters, H. P., Fuller, R. J., Hoblyn, R. A., Wright, M. T., Cowie, N. \& Bowden, C. G. R. 1996. The Woodlark Lullula arborea in Britain: population trends, distribution and habitat occupancy. Bird Study 43: 172-187.

This article is protected by copyright. All rights reserved. 
Stanbury, A., Brown, A., Eaton, M., Aebischer, N., Gillings, S., Hearn, R., Noble, D., Stroud, D. \& Gregory, R. 2017. The risk of extinction for birds in Great Britain. Br. Birds 110: 502-517.

van den Berg, L. J. L., Bullock, J. M., Clarke, R. T., Langston, R. H. W. \& Rose, R. J. 2001. Territory selection by the Dartford warbler (Sylvia undata) in Dorset, England: the role of vegetation type, habitat fragmentation and population size. Biol. Conserv. 101: 217-228.

Wright, L. J., Hoblyn, R. A., Sutherland, W. J. \& Dolman, P. M. 2007. Reproductive success of Woodlarks Lullula arborea in traditional and recently colonized habitats. Bird study 54: 315323.

\section{SUPPORTING INFORMATION}

Additional Supporting Information may be found in the online version of this article:

Appendix S1: Site information

Appendix S2: Treatments

Figure S1: Study site

Figure S2: Complex-mosaic subplots

Figure S3: Territories per plot-year

Table S1: Plant indicators

Table S2: Strata

Table S3: Model simplification

Table S4: Candidate models

Table S5: Abundance models

Table S6: Subplot model

This article is protected by copyright. All rights reserved. 


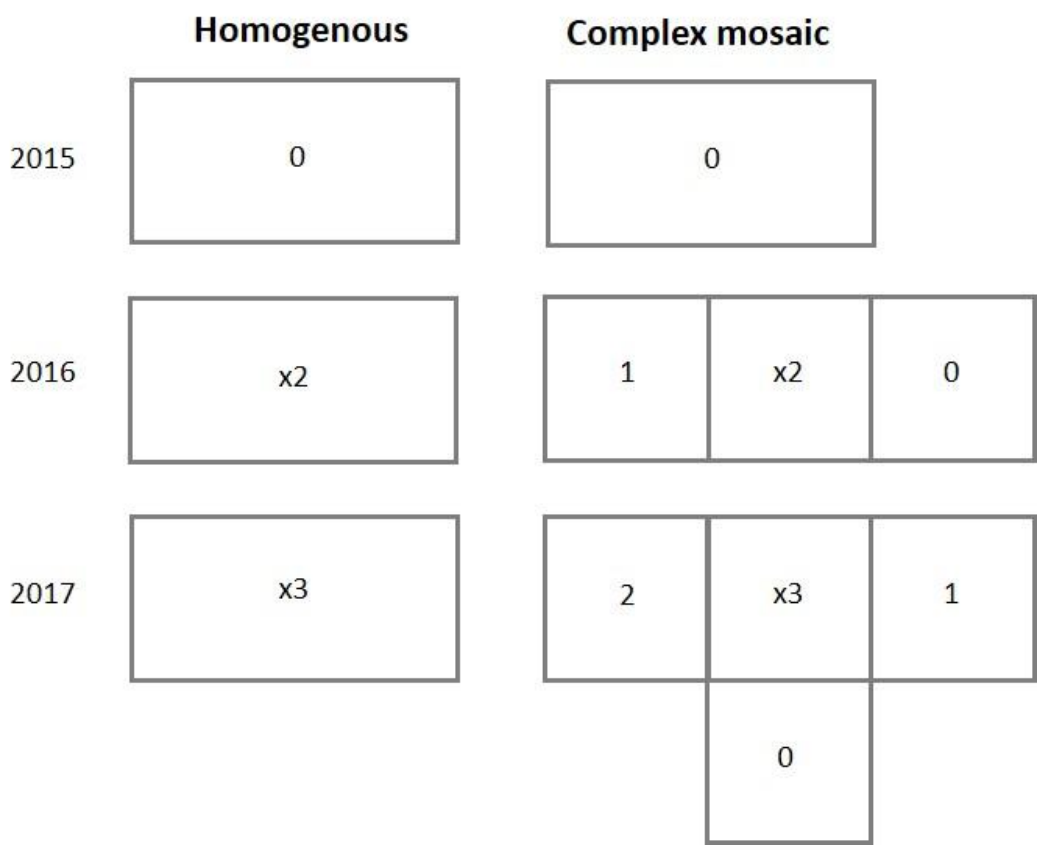

Figure 1. Development of homogenous and complex-mosaic plots over three years (2015-2017).

Numbers denote the age/disturbance frequency of each plot/subplot; 0: first-time-cultivated; 1 :

one-year-old fallow; 2: two-year-old fallow; $x 2$ and $x 3$ : annually-cultivated in each of two and three consecutive years, respectively. See Figure S2 for example photographs and \% bare ground estimates for each complex-mosaic sub-treatment in 2017.

This article is protected by copyright. All rights reserved. 


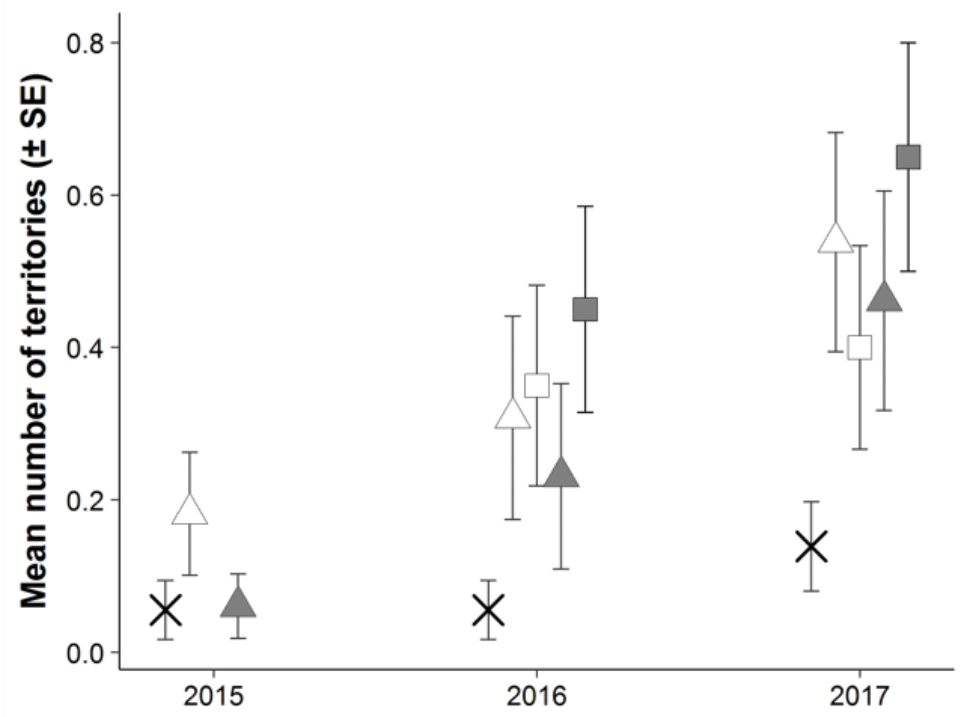

\section{Legend}

$\triangle$ Shallow cultivated homogeneous

- Shallow cultivated complex mosaic

$\Delta$ Deep cultivated homogeneous

- Deep cultivated complex mosaic

$\times \quad$ Control

Figure 2. Mean $( \pm$ se) number of Woodlark territories per plot $(n=102)$ for ground-disturbance treatments and controls in each of 2015, 2016 and 2017.

This article is protected by copyright. All rights reserved. 


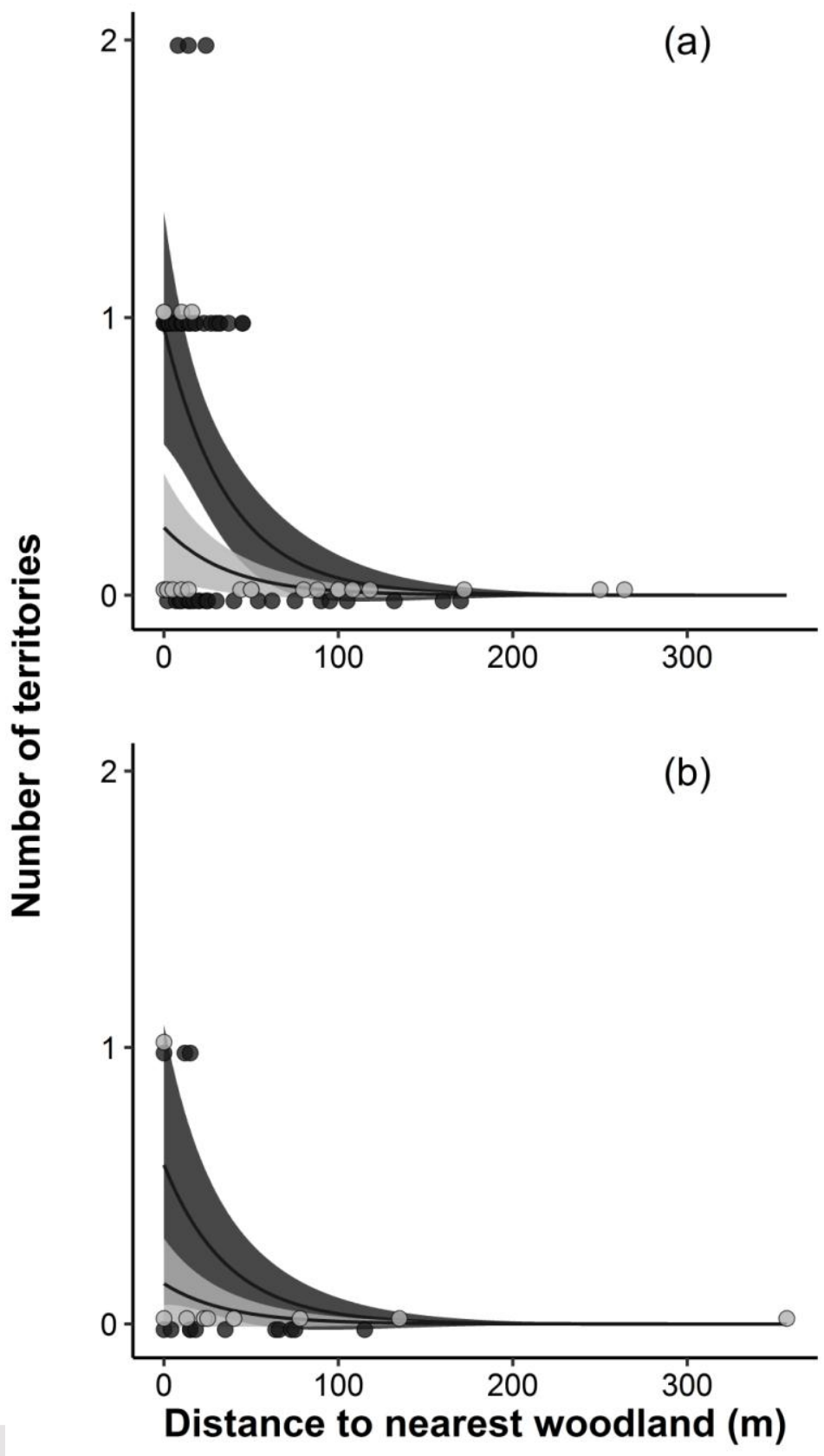

Figure 3. Predicted Woodlark Lullula arborea abundance in 2017 (the final year of the experiment) across treated (dark grey, $n=66$ ) and control (light grey, $n=36$ ) plots in relation to distance to the nearest woodland, for (a) calcareous, intermediate and young grass-heath and (b) ancient acid grassheath. Predictions are based on multi-model inference (Table S5). Lines and shading represent predicted means and $95 \%$ confidence intervals, respectively. Circles show individual data points.

This article is protected by copyright. All rights reserved. 


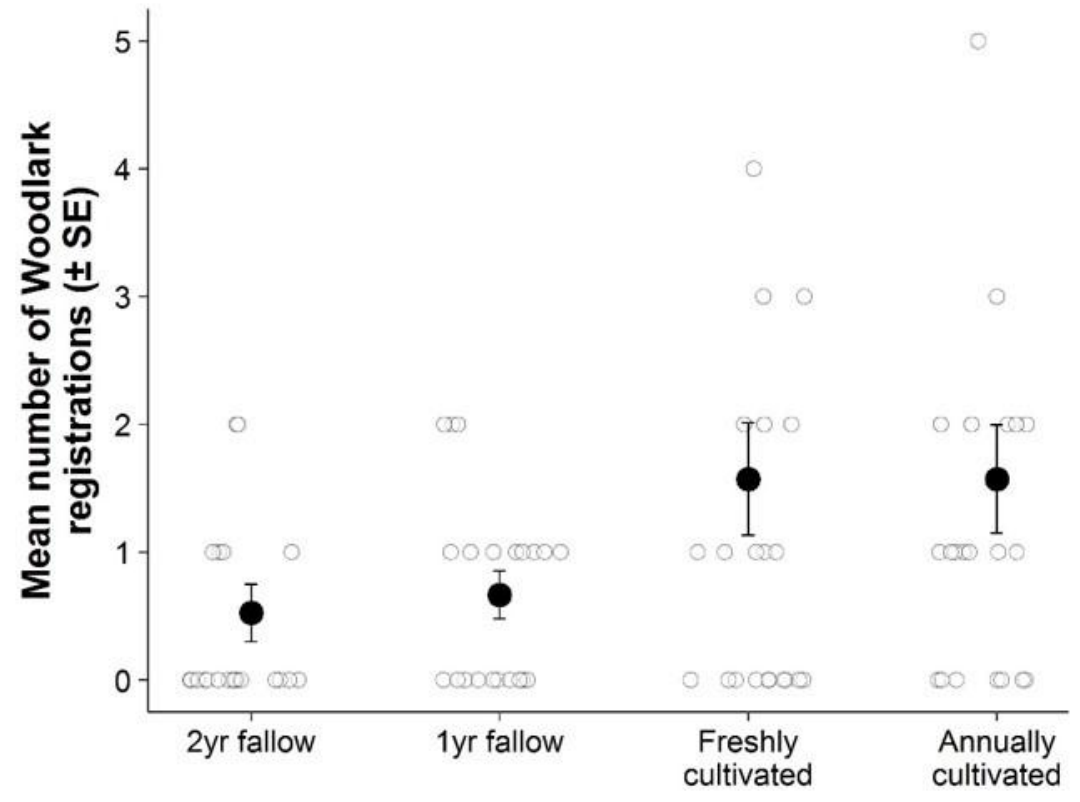

Figure 4. Mean number of Woodlark registrations per sub-treatment (filled symbol) across 84 subplots from 21 occupied complex-mosaic plots in 2017 (11 deep-cultivated, 10 shallow-cultivated). Bars represent \pm se, unfilled circles show individual data points.

This article is protected by copyright. All rights reserved. 